\title{
Provider Perspectives on Quality Payment Programs Targeting Diabetes in Primary Care Settings
}

Laura F. Garabedian, PhD, MPH, Dennis Ross-Degnan, ScD, and James F. Wharam, MB, BCh, BAO, MPH

\begin{abstract}
Public and private insurers increasingly use quality payment programs as a tool to improve quality of care in primary care settings. However, little is known about primary care providers' perspectives on whether and how quality payment programs improve diabetes quality of care. In this qualitative study, the authors conducted semistructured interviews and focus groups with 23 providers from March to June 2015. Transcripts were analyzed to identify key themes using the immersion-crystallization method. Almost all of the providers believed that insurers play a meaningful role in improving quality of care for diabetes patients. Most thought that insurers' efforts are more effective when channeled through providers and delivery systems rather than directed at patients. Providers generally believed that quality payment programs have had a positive impact on quality of diabetes care, although provider views were not evidence based. Providers in practices in which quality payment programs were believed to have had a positive impact stated that the programs provided financial incentives and resources for improved population health management systems and additional staff. Conversely, most providers did not believe that quality payment programs have had any impact via direct financial incentives to individual physicians. A few providers were skeptical about the impact of quality payment programs and noted negative consequences that they had observed. Providers recommended strategies to improve quality payment programs (eg, refine quality measures, provide regular feedback on quality and costs) and additional strategies that insurers could consider to address provider- and patient-level barriers to high-quality diabetes care.
\end{abstract}

Keywords: quality payment program, qualitative research, diabetes

$\mathbf{P}$ UBLIC AND PRIVATE INSURERS increasingly use quality payment programs as a tool to improve quality of care in primary care settings. Quality payment models include bonus payments for meeting quality benchmarks (ie, pay-forperformance) and alternative payment models such as accountable care organizations (ACOs), which tie provider risk sharing to cost and quality targets. ${ }^{1,2}$ The economic theory underlying quality payment programs is that financial rewards (or risks) incentivize physicians to implement changes in practice organization or behavior that help to translate existing knowledge about high-quality care into practice. Currently, half of primary care physicians receive payments based on quality of care or patient experience from public or private payers. ${ }^{3}$ By 2016, 28.3 million people in the United States were covered by an accountable care contract under Medicare, Medicaid, or a commercial insurer. ${ }^{4}$

Diabetes is often a focus of quality payment programs because it is a highly prevalent ${ }^{5}$ and costly ${ }^{6}$ disease, and key diabetes processes of care and outcomes are well defined and measureable. The National Committee for Quality Assurance's Healthcare Effectiveness Data and Information Set (HEDIS) measures, which are used by more than $90 \%$ of health plans in the United States, ${ }^{7}$ contain multiple metrics for comprehensive diabetes care that are commonly used in quality payment programs, including: glycated hemoglobin A1c (HbA1c) testing and control, blood pressure testing and control, eye exams, and medical attention for nephropathy.

Despite their popularity, there is mixed evidence on whether provider financial incentives lead to improved quality of diabetes care. Most quality payment programs are voluntary (ie, providers choose to participate) and therefore difficult to evaluate because of provider selection bias. ${ }^{8,9}$ The most robust quantitative studies have shown quality-based bonus payments have no or little impact on improving processes of care or outcomes in primary care settings, either in general or for diabetes. ${ }^{8,10-14} \mathrm{~A}$ recent randomized controlled trial, which included patients with diabetes, found that physician financial incentives had no impact on lowering low-density

Department of Population Medicine, Harvard Medical School and Harvard Pilgrim Health Care Institute, Boston, Massachusetts. 
lipoprotein (LDL) levels or increasing medication adherence. ${ }^{15}$ There also is mixed evidence of the impact of alternative payment models on quality of diabetes care. A study of the 1-year impact of Medicare ACOs found that although Pioneer ACOs improved modestly on preventive services for diabetes (ie, HbA1c hemoglobin testing, LDL cholesterol testing, diabetic retinal examination) and diabetes-related hospitalizations, ${ }^{16}$ Shared Savings ACOs, the most popular ACO model, only showed improvement in LDL cholesterol testing rates, ${ }^{17}$ which is no longer a HEDIS measure. An evaluation of the Blue Cross Blue Shield of Massachusetts (BCBS) Alternative Quality Contract (AQC), a precursor to Medicare ACOs that employs a similar shared-savings model plus additional quality bonuses, found that the AQC practices had evidence of improved diabetes outcomes, including greater control of HbA1c, LDL cholesterol, and blood pressure, compared to practices in control states. ${ }^{18}$

Feedback from primary care providers is important to understand the impact of provider financial incentives and to design effective payment models. Previous studies have examined primary care providers' views on the ethics of payfor-performance, ${ }^{19}$ the design and implementation of pay-forperformance schemes, ${ }^{20-23}$ and the impact of ACOs on physicians' personal and professional lives. ${ }^{24}$ Studies also have examined practice leaders' views on the potential benefits and barriers to joining ACOs, ${ }^{25}$ the decision to enter risk-sharing contracts, ${ }^{26}$ and organizational changes in response to pay-for-performance or risk-sharing contracts. ${ }^{26,27}$ A Commonwealth Fund and Kaiser Family foundation survey found that primary care physicians were skeptical about the impact of new payment models, such as ACOs, on quality of care. ${ }^{3}$ However, no studies have examined frontline primary care providers' views on if and how quality payment programs have changed the way they deliver care and how these changes have impacted quality of care, in general or specifically for diabetes. Little is known about what aspects of quality payment programs and practices' internal management of these programs facilitate or create barriers to high quality of care. ${ }^{8}$ The objective of this study was to assess primary care providers' perspectives on whether and how quality payment programs improve diabetes quality of care and to elicit provider recommendations for improving financial incentive programs. Providers' views also were sought on how to define diabetes quality of care and on the insurers' role in improving diabetes quality of care.

\section{Methods}

For this qualitative study, the study team conducted 30 - to 45-minute phone interviews and 60-minute focus groups with primary care providers in Massachusetts and New Hampshire between March and June 2015. The team recruited a convenience sample of providers who care for patients insured by Harvard Pilgrim Health Care (HPHC), a nonprofit insurer with approximately 1.2 million members in New England. To attain diversity in views, providers were sought from different practice types (eg, practice size, affiliation with delivery system) and with varied experience with quality payment programs.

The study team developed a semi-structured interview and focus group guide (Supplemental Data), which elicited provider perspectives in 3 areas: (1) definition of diabetes quality of care and barriers to providing high-quality care, (2) insurers' role in improving diabetes quality of care, and (3) the role of financial incentives from insurers in improving diabetes quality of care. All interviews and focus groups were recorded and transcribed. The team analyzed the transcripts using the immersion-crystallization method, ${ }^{28}$ which involves iterative systematic review of interview transcripts (immersion) to identify key themes and insights from the data (crystallization). Key themes are emphasized in the results.

This study was approved by the HPHC Institutional Review Board. Informed consent was obtained from all participants at the beginning of the interviews and focus groups. Participants received a small honorarium for participation.

\section{Results}

\section{Participant characteristics}

The study team conducted 10 individual interviews and 2 focus groups, with 6-7 providers each. Table 1 describes the 23 provider participants from 12 practices. All of the interviewees and the majority of focus group participants were physicians (19 doctors of medicine and 1 doctor of osteopathic medicine); 3 focus group participants were mid-level providers (2 nurse practitioners [NPs] and 1 physician assistant [PA]). Seven interviewees practiced in Massachusetts, 3 practiced in New Hampshire, and a focus group was conducted in each state. Almost all of the physician participants had training in internal medicine or family medicine and practiced in a primary care setting. One endocrinologist was interviewed who was in charge of quality at a diabetes specialty center and involved in efforts to improve primary health care delivery. One internal medicine physician had recently moved from a primary care practice to a rehabilitation facility. The remaining 21 interviewees provided care in 10 primary care practices.

Most primary care practices were affiliated with large, integrated health care entities such as multispecialty practices or physician-hospital organizations; only 2 interviewees, both from New Hampshire, were from smaller independent practices. All providers had a pay-for-performance (ie, bonus payment combined with fee-for-service) contract with at least 1 insurer and most were in risk-sharing contracts. Of the 10 primary care practices, 9 were in a Medicare ACO (6 Pioneer, 2 Shared Savings, and 2 in a Next Generation ACO). ${ }^{29}$ All of the Massachusetts practices were in the BCBS AQC, and many also were in risk-based contracts with HPHC or other commercial insurers in the state. Therefore, most feedback was on physician financial incentives within risk-based contracts or a combination of risk-based and bonus payment models, although most physicians referred to both models interchangeably as "pay for performance."

\section{Provider views on diabetes quality of care}

Providers were first asked to define high quality of diabetes care and to describe barriers to attaining such care. Providers' definition of quality of care focused both on common quality measures and on patient-centered care. 
Table 1. Characteristics of Interview and Focus Group Participants ( $\mathrm{N}=23$ Providers in 12 Practices)

\begin{tabular}{|c|c|}
\hline Provider characteristics & $\begin{array}{c}\text { Number } \\
\text { of providers (\%) }\end{array}$ \\
\hline \multicolumn{2}{|l|}{ Provider Type } \\
\hline $\begin{array}{l}\text { Physician (doctor of medicine } \\
\text { or doctor of osteopathic medicine) }\end{array}$ & $20(87 \%)$ \\
\hline $\begin{array}{l}\text { Mid-level (physician assistant } \\
\text { or nurse practitioner) }\end{array}$ & $3(13 \%)$ \\
\hline $\begin{array}{l}\text { Specialty: Internal Medicine } \\
\text { or Family Practice }\end{array}$ & $22(96 \%)^{*}$ \\
\hline Female & $11(48 \%)$ \\
\hline \multicolumn{2}{|l|}{ State } \\
\hline Massachusetts & $14(61 \%)$ \\
\hline New Hampshire & $9(39 \%)$ \\
\hline Primary Care Practice* & $\begin{array}{r}21(91.3 \%) \\
\text { [10 of } 12 \\
\text { practices] }\end{array}$ \\
\hline $\begin{array}{l}\text { Practice characteristics (of } 10 \\
\text { primary care practices } * \text { ) }\end{array}$ & $\begin{array}{c}\text { Number } \\
\text { of practices }(\%)\end{array}$ \\
\hline \multicolumn{2}{|l|}{ Practice Organization } \\
\hline Multispecialty group & $4(40 \%)$ \\
\hline Hospital PHO & $3(30 \%)$ \\
\hline IPA & $2(20 \%)$ \\
\hline Quality Payment Program Contracts & $23(100 \%)$ \\
\hline $\begin{array}{l}\text { Pay-for-performance contract with } \\
\text { at least one insurer }\end{array}$ & $23(100 \%)$ \\
\hline \multicolumn{2}{|l|}{ Medicare ACO } \\
\hline Pioneer & $6(60 \%)$ \\
\hline $\begin{array}{l}\text { Shared Savings or Next } \\
\text { Generation }\end{array}$ & $3(30 \%)$ \\
\hline BCBS AQC (of 7 MA practices) & $7(100 \%)$ \\
\hline
\end{tabular}

*One endocrinologist was interviewed and 1 internal medicine physician had recently moved from a primary care practice to a rehabilitation facility. The remaining 21 interviewees provided care in 10 primary care practices.

ACO, Accountable Care Organization; BCBS AQC, Blue Cross Blue Shield of Massachusetts Alternative Quality Contract; IPA, independent practice association; PHO, physician-hospital organization.

One interviewee stated that quality is the "intersection of what is recommended to do technically, in terms of getting risk factors measured and under control, with patientcentered factors around what the patient can or is willing to do or could be expected to do." Most providers listed commonly-used guideline recommended quality measures (eg, HEDIS measures, American Diabetes Association guidelines) and mentioned that patients' associated laboratory test values should be under control. One provider (the endocrinologist) questioned current clinical guidelines, acknowledging that recommended diabetes quality measures are "easy or readily available, but not necessarily [as] closely connected to the evidence base as they have been before. The last five to eight years of clinical trials came out and the guidelines got a lot more complicated, unfortunately." Providers also emphasized elements of patient-centered care, including that a patient: "feels $\mathrm{OK}$ " and "is able to have a normal and productive, comfortable life"; understands diabetes and how to manage it; is engaged in his or her care; and does not develop complications. According to the providers, high-quality patient-centered care requires providing a comprehensive package of services to help patients manage the disease, including nutrition, medication, lab tests, and counseling.

Providers identified the need to overcome both provider/ delivery system-level and patient-level barriers to improve quality of diabetes care. Provider/delivery system-level barriers included: pressures on physician time, lack of reimbursement for comprehensive care ("the foundations of diabetes therapies aren't compensated"), lack of ancillary providers (eg, diabetes educators, nutritionists, clinical coordinators), lack of care coordination and management, and poor doctor-patient communication. Patient-level barriers perceived by physicians included: missed routine office visits, lack of time to attend appointments, lack of geographic access to ancillary providers and specialists, high out-of-pocket costs ("it's the finances that create the gaps for these patients"), lack of knowledge about diabetes and its consequences, denial about the severity and consequences of their conditions, lack of motivation to improve behavior, low engagement, and nonadherence to recommended medications and lifestyle changes.

\section{Insurers' role in improving diabetes quality of care}

Almost all of the providers believed that insurers play a meaningful role in improving quality of care for diabetes patients. Many providers believed that insurers share their interest in improving quality of care: "They're footing the bill; they want to get good value" and, "It's everybody's benefit" to improve quality of care. However, most providers believe that insurers' efforts are more effective when channeled through providers and delivery systems rather than directed at patients: "I think that the patients have much more confidence in their providers than they do in their insurers in general... So I think anything the insurers can do that looks like it's coming through us is better." Existing insurer programs directed at patients, such as patient letters (eg, reminders to seek care) and wellness or disease management programs, were viewed as generally ineffective and duplicative. Providers were more favorable about insurer strategies targeted at providers and practices, such as quality reporting and provider payment programs. However, provider letters and quality reports from insurers were commonly viewed as duplicative and often inferior to data from the practices' electronic medical record (EMR) and population health management tools. However, providers did value information from insurers on care that their patients receive outside of their practices that is not captured in the EMR (eg, eye exams, prescription fills) and a few providers speculated that insurers' quality reports may be more useful for smaller, less technologically-resourced practices.

\section{Insurers' use of quality payment programs to improve diabetes quality of care}

All providers believed that quality payment programs had influenced the delivery of care for their patients with diabetes and most believed that provider financial incentives have had a positive impact. In practices where quality payment programs were believed to have had a positive impact, providers stated that the programs provided financial incentives and resources for improved population health management 
systems and additional staff. Many Massachusetts providers mentioned that the BCBS AQC, specifically, spurred these changes. Physicians reported that their practices had implemented systems for population health management, such as a centralized database of the entire patient population with diabetes (ie, diabetes registry or roster), patient outreach and appointment scheduling systems, or clinical support tools, such as customized EMR dashboards that provide reminders for routine diabetes care and highlight needed care. One participant noted: "The main change is... the population management concept. Just because the patient isn't in front of you in the office does not mean that you're not worried about them... Instead of just thinking about... one patient in front of us, who we've always felt like we took good care of, we are also thinking about the other 2499 patients who aren't in our office right now who have unmet medical needs.'

Additional staff hired using resources from quality payment programs included mid-level providers (NPs, PAs) and ancillary staff (ie, care managers, clinical coordinators, diabetes educator, nutritionists): "[The insurer] has probably been our biggest payer and one of our bigger contracts and it was through that program that we were able to hire the clinical care coordinator... [The insurer] doesn't pay them but... gave us the money from what we were able to accomplish to be able to hire them." Most practices that hired additional staff have implemented team-based care and devolved more responsibility to nonphysician staff. A few practices have combined team-based care with population management tools to do roster reviews (ie, care team meets regularly to review roster of diabetes patients and identify needed care). One practice uses resources from quality payment programs to hold a regular diabetes education program for physicians and other providers, while another practice uses these resources to support on-site wellness programs and a fitness facility.

Conversely, most providers do not believe that quality payment programs have had any impact via direct financial incentives to individual physicians. Although practices differed in the distribution and transparency of quality-based payments, most providers were unaware of how, or if, these payments impact their own income: "I don't know that most [providers] feel or even understand that they are being paid for the performance... I think that if you ask many of the people out there if [a financial incentive] matters they would say no... I can tell you that that money is being reinvested [and] makes a huge amount of difference." Only 1 provider from a smaller independent practice was aware of receiving direct bonus payments from an insurer.

In most practices, leadership emphasizes quality payment program goals and providers receive feedback on their performance on quality measures tied to financial incentives. Providers from large practices tended to receive quality metrics on their overall patient population, compiled by practice staff from a mix of EMR and insurer-provided data, whereas providers from smaller practices tended to receive only insurer-specific information on their performance. Some practices conducted routine meetings to explicitly discuss quality payment program goals and many shared provider-level performance results with all of the providers in the group, which providers viewed positively: "Seeing our data in comparison to our colleagues helps to get people to make changes at the individual level. We are all competitive people."
A few providers were skeptical about the impact of quality payment programs and noted negative consequences they had observed, including: a focus on patients who have insurance with a quality payment program, increased need for documentation at the expense of face time with patients, and overmanaging or overtreating patients to meet quality payment benchmarks. Although almost all providers claimed to practice without regard to insurer, a few mentioned increased outreach efforts to patients covered by the insurer with their largest quality payment contract (in terms of number of patients covered), particularly near the end of the contract year. However, providers noted positive spillovers from other insurers' quality payment programs: "I do think it spills over a lot. Once you have enough patients or you care a lot about a certain thing you tend to manage everything that way." Providers cited an increased focus on diabetes metrics in response to quality payment programs, but some questioned if the increased documentation results in improved quality. A few providers questioned whether common diabetes metrics accurately capture quality of care. The endocrinologist stated: "I think most primary care doctors feel that those dichotomous [quality] measures perhaps on one hand are easy to report, they don't all reflect the experience of, or the complexity of, diabetes care." Some providers mentioned that quality payment programs had little impact because of the already high quality of care being provided at their practice.

Provider views on the impact of quality payment programs are anecdotal, not evidence based. Although providers generally believed that the quality initiatives implemented by their practice in response to quality-based payment programs had impacted diabetes quality of care positively, none of the providers had robust empirical evidence to support this belief. Only 2 providers mentioned that they had seen data to support their claim and none cited robust evaluations or studies.

\section{Provider recommendations: quality payment programs and beyond}

Provider recommendations to improve quality payment programs focused on refining the quality metrics used and providing routine feedback (Table 2). Providers desire patient-centered measures and voiced interest in being involved in the development of quality metrics. The endocrinologist stated: "So there's a lot of tailoring that has to be a part of diabetes care to be effective... it's not... quantified and measured as much as we liked." Providers, particularly those in Medicare ACOs, also desired regular feedback on quality and costs from insurers throughout the year and not just at the end of the contract period, when it is too late to take action to improve. A few providers explicitly voiced their preference for shared-savings risk contracts over traditional pay-for-performance models.

Providers also had recommendations for insurer approaches to improving diabetes quality of care beyond quality payment programs (Table 2). Patient-focused strategies included: reducing patient cost barriers (eg, co-pays for diabetes office visits, test strips, anti-glycemic medicines), targeting outreach to less engaged patients, and providing financial incentives for patients to actively participate in diabetes self-management and care: "First of all, the patients have no idea what [insurer's risk contract] 
Table 2. Provider Recommendations to Insurers to Improve Diabetes Quality of Care

\section{Ways that insurers can improve quality payment programs} (all are provider-focused)

- Develop and implement patient-centered quality measures

- Include providers in quality measure development

- Provide regular feedback on quality measures and costs throughout the contract year

Ways that insurers can improve quality of diabetes care (beyond quality payment programs)

\section{Provider Focused}

- Provide targeted quality data (eg, on care received outside of practice)

- Coordinate with providers on patient outreach (particularly for difficult-to-engage patients and for services that are outside of primary care providers' scope of practice)

- Reimburse for care management (to support promising comprehensive, team-based approaches to care, such as diabetes roster reviews)

\author{
Patient Focused \\ - Reduce patient cost barriers \\ - Target outreach to less engaged patients \\ - Provide financial incentives \\ for patients to actively participate \\ in diabetes self-management and care
}

means... So the patients aren't really a part of this process... I don't see any incentives for them.' Provider-focused strategies included: providing targeted quality data (eg, data on care received outside of the practice); coordinating with providers on patient outreach, particularly for difficult-toengage patients and for services (eg, annual eye exams) that are outside of the primary care physician's scope of practice; and reimbursing for care management (eg, population management tools, additional staff, email). Regarding the last point, one provider mentioned that it, "would be useful to have a code that a care manager could do and then that would be even better than an insurance paid care manager because it keeps it all in the home, the medical home you know." Many providers desired increased collaboration with insurers: "We could work differently together but it would require transparency that hasn't existed."

\section{Discussion}

Most of the primary care providers in this study believe that insurers have a role in improving quality of diabetes care and think that quality payment programs are an effective strategy. The perceived positive impact of quality payment programs on diabetes quality of care is largely related to investment in practice systems and staff rather than direct financial incentives for individual physicians. Providers believe that qualitybased payments provide the incentives and resources for population health management systems and teams that can provide more comprehensive and patient-centered care.

The practice-level changes made in response to qualitybased payment programs alleviate many provider- and system-level barriers to high-quality diabetes care that the respondents identified, including: lack of physician time, lack of ancillary providers, lack of reimbursement for comprehensive care, and insufficient care coordination and management. However, although population health management systems and increased outreach by care managers may improve office visit attendance and increase patient knowledge, quality payment programs do little to address other patient-level barriers to high-quality diabetes care, including patient motivation, out-of-pocket costs, ${ }^{30}$ and other barriers to adherence.
Most providers in this study did not have major concerns about the potential negative consequences of quality payment programs. Although some providers voiced concerns about the incentive to focus on patients in quality payment contracts, many noted positive spillover from these arrangements (ie, practice-level changes incentivized by a risk-based contract from a large insurer may lead to changes in care for all patients, regardless of insurance type). However, an evaluation of the potential spillover of the BCBS AQC, a risk-based contract with a commercial insurer, on Medicare patients found that the AQC was associated with improved rates of LDL testing among Medicare patients, but no change in other diabetes process and outcome measures. ${ }^{31}$ The spillover on other commercially-insured patients is unknown and should be examined. The providers in this study did not perceive that quality payment programs led to avoidance of high-risk or noncompliant patients, ${ }^{32}$ and no providers mentioned that striving to achieve threshold levels of diabetes quality measures, which may be inappropriate for some patients, led to adverse outcomes. ${ }^{33}$

Providers' perceptions that quality payment programs improved quality of diabetes care were largely anecdotal and no definitive statements can be made about the impact of these programs on diabetes quality of care. However, prior studies, in which health care leaders in Massachusetts were interviewed, corroborate the present study findings that practices made infrastructure and organizational changes to facilitate population health management in response to pay-forperformance and alternative payment programs. ${ }^{26,27}$ And, there is some evidence that these strategies improved quality of care and outcomes. Many of the practices in the present study were early adopters of the BCBS ACQ, which has been shown to improve diabetes outcomes, ${ }^{18}$ and an earlier systematic review found that quality improvement strategies for diabetes management that target health systems, such as case management and changes to the primary care team, were associated with improved glycemic control, LDL cholesterol levels, and blood pressure. ${ }^{14}$ The present study provides important frontline primary care physician perspectives on these changes in care delivery and deeper insights about how these changes may improve quality of diabetes care. Future research should empirically examine whether the practice strategies, or 
combinations of strategies, that were incentivized by quality payment programs actually improve quality of diabetes care. Some quality improvement approaches mentioned by the providers in this study seem particularly promising, such as routine roster reviews of diabetes patients by the clinical team.

Provider recommendations for insurer quality payment programs focused on improving the relevance of the quality measures used and on ways in which insurers could more efficiently supply quality information to providers. Providers desired diabetes quality measures that are patient-centered and voiced interest in being involved in the development of such quality metrics. It will be important for quality measures to reflect current clinical knowledge, which suggests less focus on HbAlc targets and more on personalized goals for glycemic control. ${ }^{34}$ Providers also indicated that insurers and providers could collaboratively explore strategies to overcome patient barriers to care, through strategies such as reimbursement for care management or intensive behavioral therapies and patient financial incentives for diabetes care and self-management. ${ }^{15,35,36}$ However, patient-focused strategies should be evaluated carefully for potential unintended consequences (eg, coersion of low-income patients).

\section{Limitations}

This study has several limitations. The study team assessed a small sample of providers, intending to be the first to capture primary care providers' perceptions and recommendations about how health insurers can use quality payment and other approaches to improve the quality of diabetes care. Thus, it was not meant to be representative and the findings have limited generalizability. Most of the providers in the sample were in large practices within integrated delivery networks and/or multispecialty practices and most were in Massachusetts, which is a leader in health care payment innovation. ${ }^{37,38}$ The experiences of the New Hampshire providers, who were more likely to be in smaller practices that were newer to risk-based payment models, may be more representative of other US regions. It is unlikely that smaller practices have the resources and capacity to make similar investments in practice systems and staff that were observed in this study. In a nationwide survey, primary care providers were more skeptical than present study respondents about the impact of quality metrics, information technology, nonphysician clinicians, and alternative payment models. ${ }^{3}$ Present study respondents may indeed have a more positive view on quality payment programs and quality initiatives, or the study may suffer from self-report bias. Future research should examine provider perspectives on these issues in other regions of the country, with particular focus on smaller practices given that more than half of family medicine physicians in the United States still work in small or solo practices. ${ }^{39}$

Although all of the providers in the sample had at least 1 quality payment contract, there was heterogeneity in the number and types of payment programs. Because providers were not asked to explicitly identify which quality payment program led to improvements in diabetes quality of care, the study team cannot specify which model provided the greatest incentives to change delivery of care. However, nearly all of the providers were part of an ACO and/or the BCBS AQC, and many spoke specifically about their experience in risk-sharing contracts. Therefore, the results are likely most relevant to alternative payment models such as
ACOs and global payment models and not to traditional pay-for-performance models (ie, bonus payments plus fee-for-service). The team also was unable to compare the effects of individual- and practice-level financial incentives. Other research suggests that financial incentives for individual physicians are more effective than practice-level or combined physician and practice incentives. ${ }^{40}$ However, in the present study, providers saw benefit in what were primarily practice-level incentives.

\section{Conclusions}

Primary care providers in this study generally believed that insurers' quality payment programs have improved the quality of diabetes care in their practices, mainly by providing incentives and resources for practice-level quality improvement initiatives. Providers also suggested concrete insurer approaches that could improve quality payment programs and additional strategies that insurers could consider to address provider- and patient-level barriers to highquality diabetes care. However, there is a need for more empirical evidence to understand the impact that these existing and recommended initiatives have on diabetes quality of care and patient-centered outcomes.

\section{Acknowledgments}

We gratefully acknowledge the providers who participated in the study interviews and focus groups; Harvard Pilgrim Health Care leaders who facilitated the study; and Beverly Adade, who served as a research assistant on the project.

\section{Author Disclosure Statement}

The authors declare that there are no conflicts of interest. This study was funded by National Institute of Diabetes and Digestive Kidney Diseases-funded Health Delivery Systems Center for Diabetes Translational Research [P30-DK092924].

\section{Supplementary Material}

Supplementary Data

\section{References}

1. Wynne B. For Medicare's new approach to physician payment, big questions remain. Health Aff (Millwood) 2016; 35:1643-1646.

2. Centers for Medicare and Medicaid Services. Quality Payment Program. 2017. https://qpp.cms.gov Accessed June 12, 2017.

3. Ryan J, Doty MM, Hamel L, Norton M, Abrams MK, Brodie M. Primary care providers' views of recent trends in health care delivery and payment. New York: Commonwealth Fund, 2015.

4. Muhlestein D, McClellan M. Accountable Care Organizations in 2016: Private and Public-Sector Growth and Dispersion. 2016. https://www.healthaffairs.org/do/10.1377/ hblog20160421.054564/full/ Accessed August 9, 2018.

5. Geiss LS, Wang J, Cheng YJ, et al. Prevalence and incidence trends for diagnosed diabetes among adults aged 20 to 79 years, United States, 1980-2012. JAMA 2014;312:1218-1226.

6. American Diabetes Association. Economic costs of diabetes in the U.S. in 2017. Diabetes Care 2018;41:917-928. 
7. National Committee for Quality Assurance. HEDIS and Quality Compass. www.ncqa.org/HEDISQualityMeasurement/ WhatisHEDIS.aspx Accessed June 12, 2017.

8. Scott A, Sivey P, Ait Ouakrim D, et al. The effect of financial incentives on the quality of health care provided by primary care physicians. Cochrane Database Syst Rev 2011:CD008451.

9. Naci H, Soumerai SB. History bias, study design, and the unfulfilled promise of pay-for-performance policies in health care. Prev Chronic Dis 2016;13:E82.

10. Eijkenaar F, Emmert M, Scheppach M, Schoffski O. Effects of pay for performance in health care: a systematic review of systematic reviews. Health Policy 2013;110:115-130.

11. Roland M, Olesen F. Can pay for performance improve the quality of primary care? BMJ 2016;354:i4058.

12. Serumaga B, Ross-Degnan D, Avery AJ, et al. Effect of pay for performance on the management and outcomes of hypertension in the United Kingdom: interrupted time series study. BMJ 2011;342:d108.

13. Houle SK, McAlister FA, Jackevicius CA, Chuck AW, Tsuyuki RT. Does performance-based remuneration for individual health care practitioners affect patient care?: a systematic review. Ann Intern Med 2012;157:889-899.

14. Tricco AC, Ivers NM, Grimshaw JM, et al. Effectiveness of quality improvement strategies on the management of diabetes: a systematic review and meta-analysis. Lancet 2012;379:2252-2261.

15. Asch DA, Troxel AB, Stewart WF, et al. Effect of financial incentives to physicians, patients, or both on lipid levels: a randomized clinical Trial. JAMA 2015;314:1926-1935.

16. McWilliams JM, Chernew ME, Landon BE, Schwartz AL. Performance differences in year 1 of pioneer accountable care organizations. N Engl J Med 2015;372:1927-1936.

17. McWilliams JM, Hatfield LA, Chernew ME, Landon BE, Schwartz AL. Early performance of accountable care organizations in Medicare. N Engl J Med 2016;374:2357-2366.

18. Song Z, Rose S, Safran DG, Landon BE, Day MP, Chernew ME. Changes in health care spending and quality 4 years into global payment. N Engl J Med 2014;371:1704-1714.

19. Wharam JF, Paasche-Orlow MK, Farber NJ, et al. High quality care and ethical pay-for-performance: a Society of General Internal Medicine policy analysis. J Gen Intern Med 2009;24:854-859.

20. Chien AT, Colman MW, Ross LF. Qualitative insights into how pediatric pay-for-performance programs are being designed. Acad Pediatr 2009;9:185-191.

21. Wharam JF, Frank MB, Rosland AM, et al. "Pay-forperformance" as a quality improvement tool: perceptions and policy recommendations of physicians and program leaders. Qual Manag Health Care 2011;20:234-245.

22. Kondo KK, Damberg CL, Mendelson A, et al. Implementation processes and pay for performance in Healthcare: a systematic review. J Gen Intern Med 2016;31 suppl 1:61-69.

23. Greene J, Kurtzman ET, Hibbard JH, Overton V. Working under a clinic-level quality incentive: primary care clinicians' perceptions. Ann Fam Med 2015;13:235-241.

24. Stock R, Hall J, Chang AM, Cohen D. Physicians' early perspectives on Oregon's coordinated care organizations. Healthc (Amst) 2016;4:92-97.

25. Ortiz J, Bushy A, Zhou Y, Zhang H. Accountable care organizations: benefits and barriers as perceived by rural health clinic management. Rural Remote Health 2013;13:2417.

26. Mechanic RE, Santos P, Landon BE, Chernew ME. Medical group responses to global payment: early lessons from the "alternative quality contract" in Massachusetts. Health Aff (Millwood) 2011;30:1734-1742.

27. Mehrotra A, Pearson SD, Coltin KL, et al. The response of physician groups to $\mathrm{P} 4 \mathrm{P}$ incentives. Am J Manag Care 2007;13:249-255.

28. Borkan J. Immersion/crystallization. In: Crabtree BF, Miller WL, eds. Doing qualitative research. Thousand Oaks, CA: Sage, 1999:179-194.

29. Centers for Medicare and Medicaid Services. Innovation Models. 2017. https://innovation.cms.gov/initiatives/index .html - views = models Accessed April 11, 2018.

30. Wharam JF, Zhang F, Eggleston EM, Lu CY, Soumerai S, Ross-Degnan D. Diabetes outpatient care and acute complications before and after high-deductible insurance enrollment: a natural experiment for translation in diabetes (NEXT-D) study. JAMA Intern Med 2017;177:358-368.

31. McWilliams JM, Landon BE, Chernew ME. Changes in health care spending and quality for Medicare beneficiaries associated with a commercial ACO contract. JAMA 2013;310:829-836.

32. Roland M, Dudley RA. How financial and reputational incentives can be used to improve medical care. Health Serv Res 2015;50 suppl 2:2090-2115.

33. Berkowitz SA, Aragon K, Hines J, Seligman H, Lee S, Sarkar U. Do clinical standards for diabetes care address excess risk for hypoglycemia in vulnerable patients? A systematic review. Health Serv Res 2013;48:1299-1310.

34. Qaseem A, Wilt TJ, Kansagara D, Horwitch C, Barry MJ, Forciea MA. Hemoglobin A1c targets for glycemic control with pharmacologic therapy for nonpregnant adults with type 2 diabetes mellitus: a guidance statement update from the American College of Physicians. Ann Intern Med 2018; 168:569-576.

35. Baicker K, Rosenthal M. Shared savings, shared decisions, and incentives for high-value medical care. JAMA Intern Med 2014;174:2014-2015.

36. Herman WH, Rothberg AE. Prevalence of diabetes in the United States: a glimmer of hope? JAMA 2015;314:10051007.

37. Song Z, Landon BE. Controlling health care spending - the Massachusetts experiment. N Engl J Med 2012;366:15601561.

38. Centers for Medicare and Medicaid Services. Fast Facts: All Medicare Shared Savings Program (Shared Savings Program) ACOs and Pioneer ACOs. 2015. https://www.cms.gov/Medi care/Medicare-Fee-for-Service-Payment/sharedsavingsprogram /Downloads/PioneersMSSPCombinedFastFacts.pdf Accessed April 11, 2018.

39. Liaw WR, Jetty A, Petterson SM, Peterson LE, Bazemore AW. Solo and small practices: a vital, diverse part of primary care. Ann Fam Med 2016;14:8-15.

40. Petersen LA, Simpson K, Pietz K, et al. Effects of individual physician-level and practice-level financial incentives on hypertension care: a randomized trial. JAMA 2013; 310:1042-1050.

Address correspondence to:

Laura F. Garabedian, PhD, MPH Department of Population Medicine Harvard Medical School and Harvard Pilgrim Health Care Institute 401 Park Drive, Suite 401 Boston, MA 02215

E-mail: laura.garabedian@post.harvard.edu 